\title{
Diagnostic value of pipelle endometrial sampling in comparison with dilatation and curettage among patients with abnormal uterine bleeding
}

\author{
Alliratnam A.S. ${ }^{1}$, Senthil Priya S. ${ }^{1}$, Shankar R. ${ }^{2} *$ \\ ${ }^{1}$ Department of Obstetrics \& Gynaecology, VMKVMC, Salem, Tamil nadu, India \\ ${ }^{2}$ Department of Community Medicine, VMKVMC, Salem, Tamil nadu, India \\ Received: 22 January 2016 \\ Revised: 28 January 2016 \\ Accepted: 17 February 2016 \\ *Correspondence: \\ Dr. Shankar R., \\ E-mail: shnkr_radhakrishnan@yahoo.com \\ Copyright: $\odot$ the author(s), publisher and licensee Medip Academy. This is an open-access article distributed under \\ the terms of the Creative Commons Attribution Non-Commercial License, which permits unrestricted non-commercial \\ use, distribution, and reproduction in any medium, provided the original work is properly cited.
}

\begin{abstract}
Background: Dilatation and curettage (D\&C) is the gold standard for endometrial sampling, but $60 \%$ of cases less than half of the uterine cavity is curetted, with the added risk of general anesthesia, infection and perforation, whereas pipelle does not require a syringe or pump nor require general anesthesia or cervical dilatation and permits almost painless endometrial sampling. The aim and objectives of the study was to determine the reliability of pipelle device in acquiring an adequate \& representative endometrial sample comparing to $\mathrm{D} \& \mathrm{C}$ and to comparing the result of histopathological diagnosis of pipelle sampling with D\&C.

Methods: A cross-sectional study was done at Vinayaka Missions Medical College Salem between September 2014August 2015. 100 cases of AUB attending the outpatient clinic in the department of obstetrics \& gynecology were included in the study. Endometrial sampling with pipelle device was performed in 100 patients followed by formal D\&C.

Results: For obtaining the endometrial sample the sensitivity of pipelle sampling was $97 \%$ and the specificity was $100 \%$ when compared with D\&C sampling. The diagnosis made by the HPE report by the sample obtained from pipelle sample had shown a very high sensitivity, specificity, positive predictive value and negative predictive value, except for the diagnosis of endometrial polyp which the pipelle sample was not able to detect.

Conclusions: The pipelle is a safe technique of endometrial biopsy for getting an adequate endometrial sample for histopathology, with high sensitivity and specificity for endometrial pathologies and endometrial carcinoma.
\end{abstract}

Keywords: Pipelle endometrial sampling, D\&C, AUB, Biopsy

\section{INTRODUCTION}

Abnormal uterine bleeding accounts for more than $70 \%$ of all gynaecological consultations in the peri and postmenopausal years. ${ }^{1}$ The bleeding could be a sign of an underlying localized condition including infection, benign and malignancy. Abnormal uterine bleeding is a common reason for gynaecological consultation. It occurs when a woman experiences a change in her menstrual blood loss, or if the degree of blood loss or vaginal bleeding pattern differs from that experienced by the age-matched general female population. Normal menstruation and normal menstrual cycle are defined according to the regularity, frequency, amount, and duration of menstrual flow. Abnormal uterine bleeding can occur due to non-structural and structural causes., ${ }^{2}$ It is an important presenting symptom of uterine cancer. Endometrial sampling for histopathology is important in the assessment of abnormal uterine bleeding.

Dilatation \& curettage (D\&C) is the gold standard for endometrial sampling, but in $60 \%$ of cases, less than half of the uterine cavity is curetted, with the added risk of general anaesthesia, infection and perforation. ${ }^{4,5}$ This has led to the advent of new and simple methods for endometrial sampling. Various devices are on the market nowadays, including the Pipelle device. ${ }^{6,7}$ The Pipelle can be used on an outpatient basis and is cost effective 
compared with D\&C. ${ }^{8}$ However, there are still concerns regarding the adequacy of the sample obtained, nonsampling of focal intrauterine lesions. ${ }^{6}$

In this context the present study was conducted to assess and compare the diagnostic accuracy of Pipelle endometrial sampling with conventional D\&C in patients with abnormal uterine bleeding.

\section{METHODS}

A cross sectional study was conducted on 100 patients with abnormal uterine bleeding over 40 years of age after getting clearance from the institutional ethics committee. Detailed clinical assessment of the patients was followed by transvaginal sonography and laboratory investigations (CBC, coagulation profile, prolactin, thyroid and liver function tests). Patients with local gynaecological cause or possibility of pregnancy or history of contraception or endometrial thickness $<4 \mathrm{~mm}$ were excluded from the study. Patients included in this study were euthyroid with normal liver function tests, normal activated partial thromboplastin time (APTT) and normal platelet count. The endometrial sampling was performed by the Pipelle device. The Pipelle was introduced without performing cervical dilatation and withdrawn outside the uterus with a rotatory movement to get the sample which was labelled as sample A. The patients were then transferred to the operative theatre for $\mathrm{D} \& \mathrm{C}$ and the obtained sample after D\&C was labelled as sample B. Both samples were sent to a pathologist, who was blinded to the methods of sampling and patients' medical history for histopathology assessment. The histopathology reports of the Pipelle sample was compared with that of the D\&C sample and the $\mathrm{D} \& \mathrm{C}$ report was considered as the gold standard.

\section{RESULTS}

Table 1: Characteristics of the study population.

\begin{tabular}{|lll|}
\hline Variables & Mean & SD \\
\hline Age (in years) & 42.22 & 6.65 \\
\hline Duration of bleeding PV (in months) & 8.23 & 2.36 \\
\hline Duration of flow (in days) & 8.5 & 3.25 \\
\hline Age of menarche (in years) & 12.65 & 0.91 \\
\hline Age at marriage (in years) & 20.63 & 2.8 \\
\hline Parity & 2.7 & 1.2 \\
\hline Endometrial thickness (in mm) & 6.86 & 2.04 \\
\hline
\end{tabular}

The basic study characteristics mean and standard deviation of the study population was reflected in table 1 . The mean age of the study population was 42.2 years and among them menorrhagia and polymenoorhoea was the chief complaints, the mean duration of bleeding per vagina was 8.23 months and the mean duration of flow in them was 8.5 days. The average parity among the women with DUB was 2.7 and their mean endometrial thickness was $6.86 \mathrm{~mm}$.
Table 2: Comparison of HPE results obtained by conventional $\mathrm{D} \& \mathrm{C}$ and pipelle device.

\begin{tabular}{|lll|}
\hline HIPE report & $\begin{array}{l}\text { Pipelle } \\
\text { sampling } \\
(\mathbf{n}=\mathbf{1 0 0})\end{array}$ & $\begin{array}{l}\text { D \& C } \\
(\mathrm{n}=\mathbf{1 0 0})\end{array}$ \\
\hline Proliferative endometrium & 53 & 49 \\
\hline Secretory endometrium & 29 & 29 \\
\hline Disordered endometrium & 9 & 10 \\
\hline Adenocarcinoma & 2 & 2 \\
\hline Polyp & 0 & 6 \\
\hline $\begin{array}{l}\text { No report (sample was not } \\
\text { obtained) }\end{array}$ & 7 & 4 \\
\hline
\end{tabular}

Table 3: Sensitivity, specificity, PPV and NPV of The HPE report of pipelle sampling in comparison with $D$ \& C.

\begin{tabular}{|c|c|c|}
\hline \multirow{4}{*}{$\begin{array}{l}\text { Proliferative } \\
\text { endometrium }\end{array}$} & Sensitivity & $100 \%$ \\
\hline & Specificity & $92 \%$ \\
\hline & $\begin{array}{l}\text { Positive predictive } \\
\text { value }\end{array}$ & $93 \%$ \\
\hline & $\begin{array}{l}\text { Negative predictive } \\
\text { value }\end{array}$ & $100 \%$ \\
\hline \multirow{4}{*}{$\begin{array}{l}\text { Secretory } \\
\text { endometrium }\end{array}$} & Sensitivity & $100 \%$ \\
\hline & Specificity & $100 \%$ \\
\hline & $\begin{array}{l}\text { Positive predictive } \\
\text { value }\end{array}$ & $100 \%$ \\
\hline & $\begin{array}{l}\text { Negative predictive } \\
\text { value }\end{array}$ & $100 \%$ \\
\hline \multirow{4}{*}{$\begin{array}{l}\text { Disordered } \\
\text { endometrium }\end{array}$} & Sensitivity & $90 \%$ \\
\hline & Specificity & $100 \%$ \\
\hline & $\begin{array}{l}\text { Positive predictive } \\
\text { value }\end{array}$ & $100 \%$ \\
\hline & $\begin{array}{l}\text { Negative predictive } \\
\text { value }\end{array}$ & $99 \%$ \\
\hline \multirow{4}{*}{ Adenocarcinoma } & Sensitivity & $100 \%$ \\
\hline & Specificity & $100 \%$ \\
\hline & $\begin{array}{l}\text { Positive predictive } \\
\text { value }\end{array}$ & $100 \%$ \\
\hline & $\begin{array}{l}\text { Negative predictive } \\
\text { value }\end{array}$ & $100 \%$ \\
\hline \multirow{4}{*}{ Polyp } & Sensitivity & $16 \%$ \\
\hline & Specificity & $100 \%$ \\
\hline & $\begin{array}{l}\text { Positive predictive } \\
\text { value }\end{array}$ & $100 \%$ \\
\hline & $\begin{array}{l}\text { Negative predictive } \\
\text { value }\end{array}$ & $94 \%$ \\
\hline
\end{tabular}

The comparison of the HPE results obtained by pipelle sampling and $\mathrm{D} \& \mathrm{C}$ is shown in table 2. The most common finding in both pipelle sampling and D\&C was proliferative endometrium followed by secretory and disordered endometrium. Polyp was only picked up by D\&C, whereas the pipelle sampling failed to do so. Failure of obtaining a sample was reported in $7 \%$ of the patients in pipelle sampling whereas it was $4 \%$ in D\&C. The viability of pipelle sampling in comparison with 
$\mathrm{D} \& \mathrm{C}$ is shown in table 3 by calculating sensitivity, specificity, positive predictive and negative predictive value. The sensitivity was $100 \%$ for pipelle sampling in detecting proliferative and secretory endometrium and it was $90 \%$ for the detection of disordered endometrium, whereas the sensitivity was only $16 \%$ in the detection of polyp. So the pipelle sample being a simple technique can be used as a screening procedure for obtaining endometrial sample in the patients with abnormal uterine bleeding.

\section{DISCUSSION}

Many authors concluded that the Pipelle is an accurate and acceptable outpatient sampling technique when compared with D\&C. ${ }^{9-11}$ In this study; the Pipelle device had $97 \%$ sensitivity, $100 \%$ specificity and $100 \%$ predictive values in obtaining the endometrial sample, also it was $100 \%$ accurate for diagnosing proliferative and secretory endometrium and also endometrial carcinoma.

Mechado and colleagues reviewed 1535 reports of endometrial biopsies taken from outpatients using the Cornier Pipelle, in pre- and postmenopausal patients with abnormal vaginal bleeding, to establish the accuracy of endometrial biopsy with the Cornier Pipelle in the diagnosis of endometrial cancer and atypical endometrial hyperplasia. The Cornier Pipelle was $84.2 \%$ sensitive, 99.1\% specific, $96.9 \%$ accurate, with $94.1 \% \mathrm{PPV}$ and 93.7\% NPV for detection of endometrial carcinoma and atypical hyperplasia and they concluded that endometrial biopsy taken with the Cornier Pipelle is an accurate method for diagnosis of endometrial cancer and its precursor atypical hyperplasia. ${ }^{12}$

A meta-analysis to assess the accuracy of endometrial sampling devices in detection of endometrial carcinoma and atypical hyperplasia was done by Dijkhuijen et $\mathrm{al}^{13}$. They concluded that the endometrial biopsy with the Pipelle is superior to other endometrial techniques in detection of endometrial carcinoma and atypical hyperplasia in pre- and postmenopausal women.

In the study by Abdelazim et al, ${ }^{14}$ the pipelle and D \& C were compared and the authors reported $100 \%$ sufficient sample in conventional D \& C and $97.7 \%$ for pipelle that is higher by both methods in comparison to our study. It may be due to different techniques and instruments and also pathologist's experience. In a study by Naderi and colleagues ${ }^{15}$ the sufficiency rates were $91.6 \%$ and $98.3 \%$ by pipelle and D \& C respectively. These are higher sufficient rates than our study. The study by Mousavifar et al $^{16}$ reported $94 \%$ sufficiency rate for pipelle samples that is more than results of this study. The other studies (Behnamfar et al, Fakhar et al, Bano et al) were also reported better rates for both pipelle and $D \& C$ in comparison with our study. ${ }^{17-19}$
A significant number of cases showed disordered proliferative pattern in this study. Disordered proliferative pattern lies at one end of the spectrum of proliferative lesions of the endometrium that includes carcinoma at the other end with intervening stages of hyperplasias. The term "disordered proliferative endometrium" has been used in a number of ways and is somewhat difficult to define. It denotes an endometrial appearance that is hyperplastic but without an increase in endometrial volume. ${ }^{20}$ It also refers to a proliferative phase endometrium that does not seem appropriate for any one time in the menstrual cycle, but is not abnormal enough to be considered hyperplastic. Disordered proliferative pattern resembles a simple hyperplasia, but the process is focal rather than diffuse. A higher incidence of disordered proliferative pattern was found in our study as compared to Cho Nam-Hoon et al. ${ }^{21}$

In the present study incidence of carcinoma endometrium was more common in the 51-60 years age group. The result of this study was almost similar to data mentioned by Yusuf et al and Escoffery et al in their study. ${ }^{22} \mathrm{~A}$ study done by Dangal et al. in Nepal documented a lower incidence of endometrial cancer in Nepalese woman attributing it to the practice of early childbearing and multiparty. ${ }^{23}$ Possibly, the same factors contributed to a lower incidence of carcinoma in our patients.

\section{CONCLUSIONS}

Endometrial sampling using Pipelle type device is an easy and safe method of getting tissue diagnosis, which can be done as an out-patient procedure. Pipelle is costeffective and has better patient compliance in addition to the added advantage of no anaesthesia or other procedure complications like perforation compared to D \& C.

Thus it can be considered as a first line investigation for getting an adequate endometrial sample for histology in patients with abnormal uterine bleeding with high sensitivity and specificity even for the detection of hyperplasia and malignancy.

Funding: No funding sources

Conflict of interest: None declared

Ethical approval: The study was approved by the Institutional Ethics Committee

\section{REFERENCES}

1. Spencer CP and Whitehead MI. Endometrial assessment re-visited. $\mathrm{Br} \mathrm{J}$ Obstet Gynecol. 1999;106(7):623-32.

2. Fraser IS, Critchley HO, Broder M, Munro MG. The FIGO recommendations on terminologies and definitions for normal and abnormal uterine bleeding. Semin Reprod Med. 2011;29:383-90.

3. Munro MG, Critchley HO, Broder MS, et al. FIGO Working Group on Menstrual Disorders. FIGO classification system (PALM-COEIN) for causes of 
abnormal uterine bleeding in nongravid women of reproductive age. Int J Gynaecol Obstet. 2011;113:313.

4. Telner DE, Jakubovicz D. Approach to diagnosis and management of abnormal uterine bleeding. Can Fam Physicians. 2007;53:58-64.

5. Clark TJ, Gupta JK. Endometrial sampling of gynaecological pathology. The Obstetrician and Gynaecologist. 2002;4:169-74.

6. Vigod SN, Stewart DE. Management of abnormal uterine bleeding by northern, rural and isolated primary care physicians: Part I - How are we doing? BMC Women Health. 2002;2:10.

7. Brand A, Duduc-Lissoir J, Ehlen TG, Plante M. Diagnosis of endometrial cancer in women in women with abnormal vaginal bleeding. SOGC Clinical Practice Guidelines. J Soc Obst \& Gynae Can. 2000;22:102-4.

8. Fakhar S, Saeed G, Khan AH, Alam AY. Validity of pipelle endometrial sampling in patients with abnormal uterine bleeding. Ann Saudi Med. 2008;28:188-91.

9. Chaudry A, Javaid M. Clinical usefulness of pipelle endometrial sampling. Pak Armed Forces. Med J. 2005;55:122-5.

10. Asif AZ. An acceptable outpatient technique for endometrial biopsy. J College Physician Surg Pak. 1999;9:14-6.

11. Behnamfar F, Khamehchian T, Mazoochi T, Fahiminejad T. Diagnostic value of endometrial sampling with Pipelle suction curettage for identifying endometrial lesions in patients with abnormal uterine bleeding. J Res Med Sci. 2004;3:21-3

12. Machado F, Moreno J, Carazo M, Leon J, Fiol G, Serna R. Accuracy of endometrial biopsy with the Cornier Pipelle for diagnosis of endometrial cancer and atypical hyperplasia.Eur J Gynaecol Oncol. 2003;24:279-81.

13. Dijkhuizen FP, Mol BW, Brölmann HA, Heintz AP. The accuracy of endometrial sampling in the diagnosis of patients with endometrial carcinoma and hyperplasia: a meta-analysis. Cancer. 2000;89:1765-72.

14. Abdelazim IA, Aboelezz A, Abdul Kareem AF. Pipelle endometrial sampling versus conventional dilatation \& curettage in patients with abnormal uterine bleeding. J Turkish German Gynecol Assoc.2013;14:1-5.

15. Naderi $\mathrm{T}$, Asharafganjooie $\mathrm{T}$, Bahrampoor $\mathrm{A}$, Mehrimahani I. Comparison of the diagnostic accuracy of pipelle biopsy, dilatation and curettage and hysrectomy in detection of endometrial lesions. J Kerman University Med Sci. 2006;13:159-63.

16. Mousavifar N, Delavari M, Talaei-Khoei M. Accuracy of pipelle sampler for endometrial assessment. J Babol Univ Med Sci. 2005;8:53-8.

17. Bano I, Anwar A, Tahir N, Shaheen T. Establishing reliability of pipelle endometrial biopsy in comparison to traditional curettage and future outpatient hysteroscopy. Quart Med Chan. 2011;17:32-5.

18. Behnamfar F, Khamehchian T, Mazoochi T, Fahiminejad T. Diagnostic value of endometrial sampling with pipelle suction curettage for identifying endometrial lesions in patients with abnormal uterine bleeding. J Res Med Sci. 2004;3:123-5.

19. Fakhar S, Saeed G, Khan AM, Alam A.Validity of pipelle endometrial sampling in patients with abnormal uterine bleeding. Ann Saudi Med. 2008;28:188-91.

20. Steven SG. Problems in the differential diagnosis of endometrial hyperplasia and carcinoma. Mod Pathol. 2000;13:309-27.

21. Nam-Hoon C, Chan-II P, In-Joon C. Clinicopathologic study of the endometrium. Dysfunctional uterine bleeding. Korean J Pathol. 1989;23:65-74.

22. Escoffery CT, Blake GO, Sargenat LA. Histopathological findings in women with postmenopausal bleeding in Jamaica. West Indian Med J. 2002;51:232-5.

23. Dangal G. A study of endometrium of patients with abnormal uterine bleeding at chitwan valley. Kathmandu Univ Med J. 2003;1:110-2.

Cite this article as: Alliratnam AS, Senthil Priya S, Shankar R. Diagnostic value of pipelle endometrial sampling in comparison with dilatation and curettage among patients with abnormal uterine bleeding. Int $\mathbf{J}$ Reprod Contracept Obstet Gynecol 2016;5:864-7. 